\title{
REINFORCED AND PRESTRESSED CONCRETE HOLLOW BEAMS UNDER TORSION
}

\author{
Luis F. A. BERNARDO, Jorge M. A. ANDRADE, Luiz A. PEREIRA-DE-OLIVEIRA \\ Department of Civil Engineering and Architecture, University of Beira Interior, 6201-001 Covilhã, Portugal
}

Received 05 Dec 2011; accepted 19 Apr 2012

\begin{abstract}
Recently a new rational theoretical model for beams under torsion has been proposed. This model, called Softened Membrane Model for Torsion (SMMT), is able to predict well the global behaviour of reinforced and prestressed concrete solid beams under torsion. This paper presents a study in order to check the SMMT for reinforced and prestressed concrete hollow beams under torsion. Theoretical predictions from SMMT are compared to some experimental results of hollow beams available in the literature and also with the predictions of another theoretical model previously proposed from the authors. It is shown that SMMT, with some corrections, is able to predict satisfactorily the overall behaviour of reinforced and prestressed concrete hollow beams under torsion.
\end{abstract}

Keywords: torsion, reinforced concrete, prestressed concrete, hollow beams, theoretical model.

Reference to this paper should be made as follows: Bernardo, L. F. A.; Andrade, J. M. A.; Pereira-de-Oliveira, L. A. 2013. Reinforced and prestressed concrete hollow beams under torsion, Journal of Civil Engineering and Management 19(Supplement 1): S141-S152. http://dx.doi.org/10.3846/13923730.2013.801895

\section{Introduction}

Since the original Space-Truss Analogy (STA) proposed in the beginning of last century (Rausch 1929), several further versions have been developed to lead to theoretical models for Reinforced Concrete (RC) and Prestressed Concrete (PC) beams under torsion. The STA as a high historical value and constitutes the base for torsion design of the European Model Code (since 1978) and also the American Code (since 1995).

The Variable Angle Truss-Model (VATM) (Hsu, Mo 1985a) is one of the most powerful developments of the original STA from Rausch 1929. This theory uses a non linear softened stress $(\sigma)-$ strain $(\varepsilon)$ relationship for the concrete in the struts instead of a conventional $\sigma-\varepsilon$ relationship for uniaxial compression. VATM is able to predict the global behaviour of RC and PC beams under torsion throughout the entire loading history, although very good results are observed only for high loading levels. In fact, VATM is not able to predict the torsional behaviour of beams in the loading range before cracking neither immediately after cracking.

The success of VATM to predict the points of the Torque $(T)$ - Twist $(\theta)$ curve for the ultimate behaviour is understandable, since, for high level of loading, the concrete is extensively cracked. In this stage, the theoretical model approaches the real model. For low level of loading, the beam is not extensively cracked (or not cracked at all). Furthermore, for low level loading the concrete core of solid sections (neglected in the VATM) also influences the torsional stiffness of the beams. This explains the deviations between theoretical and experimental $T-\theta$ curves.

Based on the referred previously, Bernardo (2003) and Bernardo, Lopes (2008, 2011b) developed a calculation procedure in order to predict the overall theoretical behaviour (not just the ultimate) of $\mathrm{RC}$ and $\mathrm{PC}$ beams under torsion. The theoretical approach was firstly performed by studying different behavioural states, each of one identified with the different states observed experimentally. In general, the $T-\theta$ curves obtained from laboratorial tests on RC beams (with current reinforcement ratios) under pure torsion lead to a typical $T-\theta$ curve (Figure 2). Three zones (1,2 and 3) can be differentiated. Zone 1 represents the beam's behaviour before cracking. In this stage the beam behaves linearly. After cracking, the slope of the $T-\theta$ curve decreases. The beam continues to behave approximately linearly up to a certain load level. This is Zone 2 . Zone 3 begins with a markedly nonlinear behaviour that begins with the yielding of the torsional reinforcement. These behavioural states were characterized individually by the authors by using different theories:

- Linear elastic analysis in non cracked state: Bredt's Thin-Tube Theory;

- Linear elastic analysis in cracked state: STA with an angle of $45^{\circ}$ for the concrete struts and considering linear behaviour for the materials;

- Non linear analysis: VATM. 
To make the transition between the different theoretical states, Bernardo, Lopes $(2008,2011 \mathrm{~b})$ adopted semi-empirical criteria. From the comparative analysis between the theoretical predictions from the model and the experimental results, the authors showed that the procedure was adequate to predict the global behaviour of RC and PC beams under torsion.

Despite the good results provided by the global model of Bernardo and Lopes (2008, 2011b), the authors recognize that the model is not fully rational because different torsional theories were used to characterize the behaviour of each state. This led the authors to adopt criteria to make the transition between the behavioural states, to obtain the entire $T-\theta$ curve.

Recently, Jeng and Hsu (2009) extended the Softened Membrane Model (SMM), previously developed to treat theoretically RC membrane elements under shear (Hsu, Zhu 2002), to RC beams under torsion. This analytical method takes into account the strain gradient of concrete struts in the shear flow zone by making some modifications on the constitutive relationships of concrete from the original theory. Firstly, in the tensile $\sigma-\varepsilon$ relationship of concrete (Belarbi, Hsu 1994), the precracking stiffness and the strain at peak stress was increased by $45 \%$. Secondly, the Hsu/Zhu ratio for torsion (parameter for the Poisson's effect) is taken as $80 \%$ of the Hsu/Zhu ratio for shear (Zhu, Hsu 2002). This new analytical method, called Softened Membrane Model for Torsion (SMMT), is able to predict the entire $T-\theta$ curve for all the loading levels. Jeng and Hsu (2009) compared the theoretical predictions from the SMMT with experimental data available in the literature and concluded that the predictions are generally good.

More recently, Jeng et al. (2010) extended the SMMT to treat PC members under torsion. For this purpose, the SMMT was modified in order to incorporate the initial stresses due to prestressing and the forces in the prestress reinforcement. The predicted $T-\theta$ curves from SMMT were compared with some experimental data available in the literature and it was found that the predictions are also generally good.

\section{Research significance}

In the previously referred studies, the authors (Jeng, Hsu 2009; Jeng et al. 2010) only use experimental data from solid beams under torsion to validate the SMMT. Hollow beams were excluded because their cracking torque and cracking angles of twist are somewhat lower than those of solid beams (Jeng, Hsu 2009).

Since SMMT constitutes an extension from a membrane model under shear (SMM), it is not very clear why hollow sections were not included in the referred studies. In fact, the walls of hollow sections act as membranes under shear due to the torsional forces. Furthermore, the extension of SMM to beams under torsion is made by employing the thin tube concept (Jeng, Hsu 2009). Beams with hollow sections and with thin walls can be assumed as thin tubes. Therefore, it seems to be logical that SMMT can be used to predict the torsional behaviour of hollow beams.
In this study, the SMMT is checked for RC and PC hollow beams under torsion. Theoretical predictions from SMMT are compared to some experimental results of hollow beams available in the literature and also with the predictions of another theoretical model previously proposed from the authors.

Finally, it should be noted that several studies on the torsional behaviour of RC and PC beams exist. However, the majority of these studies deal with solid beams. The number of recent studies dedicated to hollow beams under torsion is scarce (e.g. Bernardo, Lopes 2008, 2011a). This observation justifies the need for more theoretical and experimental studies about RC and PC hollow beams under torsion to support a firm theory on the behaviour of such structures.

\section{The SMMT}

This section resumes the formulation and the calculus procedure to compute the theoretical $T-\theta$ curve from SMMT. From the original studies (Jeng, Hsu 2009; Jeng et al. 2010), the formulation was rewritten in order to cover both RC and PC beams. Only longitudinal prestressing is covered since no experimental data were found in the literature for transversal prestressing.

The computation of the theoretical $T-\theta$ curve requires 4 equilibrium equations to compute the stresses (normal and shear) and the torque $T$ (Eqns (1) and (2) in Table 1), and also 5 compatibility equations to compute the strains (normal and shear), the twist $\theta$ and the effective thickness of the shear flow $t_{d}$ (Eqns (3) to (6) in Table 1).

The relationships between biaxial and uniaxial strains are given by Eqns (7) and (8) in Table 1.

The initial compressive strain in the concrete and mild steel $\left(\varepsilon_{l i}=\bar{\varepsilon}_{l i}=\bar{\varepsilon}_{1 i}=\bar{\varepsilon}_{2 i}\right)$ due to prestressing is introduced in the constitutive relationships of the materials.

To characterize the concrete in compression in the diagonal struts, a compressive $\sigma-\varepsilon$ relationship (Eqns (9) to (13) in Table 2, Wang (2006)) is adopted considering the unfavourable effect of the softening effect (coefficient $\zeta$ ). The $k_{1 c}$ parameter is an average stress factor to compute the average compressive stress of the concrete diagonal struts (Eqns (14) and (15) in Table 2) and it is obtained by integrating Eqns (9) and (10).

To characterize the concrete in tension in the diagonal ties, a tensile $\sigma-\varepsilon$ relationship is adopted (Belarbi, Hsu 1994). This $\sigma-\varepsilon$ relationship is extended in order to incorporate prestressing effect, namely the decompression stage (Eqns (16) to (21) in Table 3). As referred in Section 1, this relationship was modified to incorporate the strain gradient effect (for torsion). The pre-cracking stiffness $\left(E_{c}\right)$ and the strain at peak stress $\left(\varepsilon_{c r}\right)$ were increased by $45 \%$ (Jeng, Hsu 2009) (Eqns (22) and (23) in Table 3). To calculate the average tensile stress in the concrete diagonal ties, the initial stress state due to prestressing (compression) should be considered (Eqns (24) to (27) in Table 3). For RC members no compressive initial state exists, so the average tensile stress in the concrete diagonal ties can be computed by using an average stress factor $k_{2 c}$, as for the concrete in compression in the struts (Eqns (28) and (29) in Table 3). 
Table 1. SMMT formulation for PC beams (for RC beams: $f_{l i}=f_{p i}=\sigma_{c i}=0$ )

Softened Membrane Model for Torsion (Jeng, Hsu 2009; Jeng et al. 2010)
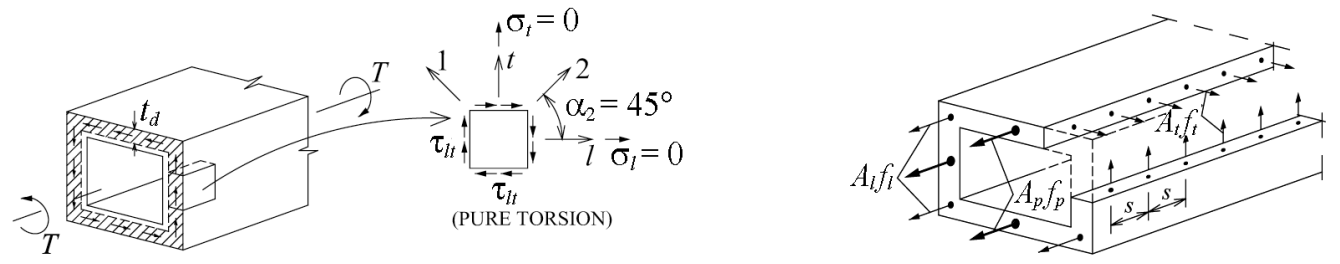

Equilibrium equations:

$$
\begin{aligned}
& \left\{\begin{array}{l}
\sigma_{l} \\
\sigma_{t} \\
\tau_{l t}
\end{array}\right\}=\left\{\begin{array}{l}
0 \\
0 \\
\tau_{l t}
\end{array}\right\}=\left[\begin{array}{ccc}
1 / 2 & 1 / 2 & 1 \\
1 / 2 & 1 / 2 & -1 \\
-1 / 2 & 1 / 2 & 0
\end{array}\right]\left\{\begin{array}{l}
\sigma_{2}^{c}- \\
\sigma_{1}^{c}- \\
\tau_{21}^{c}
\end{array}\right. \\
& \text { Compatibility equations: } \\
& \left\{\begin{array}{l}
\varepsilon_{l} \\
\varepsilon_{t} \\
\gamma_{l t} / 2
\end{array}\right\}=\left[\begin{array}{ccc}
1 / 2 & 1 / 2 & 1 \\
1 / 2 & 1 / 2 & -1 \\
-1 / 2 & 1 / 2 & 0
\end{array}\right]\left\{\begin{array}{l}
\varepsilon_{2} \\
\varepsilon_{1} \\
\gamma_{21} / 2
\end{array}\right\} ;
\end{aligned}
$$

(1) $T=2 A_{\mathrm{o}} t_{d} \tau_{l t}$.

$\theta=\frac{p_{\mathrm{o}}}{2 A_{\mathrm{o}}} \gamma_{l t}$

$$
t_{d}=\frac{1}{2(Q+4)}\left[p_{c}\left(1+\frac{Q}{2}\right)-\sqrt{\left(1+\frac{Q}{2}\right)^{2} p_{c}^{2}-4 Q(Q+4) A_{c}}\right]
$$

$$
Q=\frac{4 \bar{\varepsilon}_{2}}{\gamma_{l t}}
$$

Relationships between biaxial strains $(\varepsilon, \gamma)$ and uniaxial strains $(\bar{\varepsilon}, \bar{\gamma})$ :

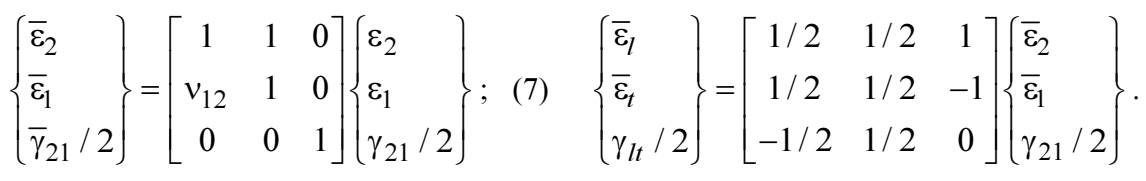

\begin{tabular}{ll}
\hline$\sigma_{c i}$ & $=$ longitudinal initial compressive stress in the concrete due to prestressing; \\
$f_{l i} ; f_{p i}$ & $=$ longitudinal initial stresses in the mild steel and prestressing steel due to prestressing; \\
$f_{l} ; f_{i} ; f_{p}$ & $=$ longitudinal and transversal stress in the mild steel; longitudinal stress in the prestressing steel; \\
$\rho_{l i} ; \rho_{p i}$ & $=$ longitudinal mild steel and prestressing steel ratios before twisting $\left(\rho_{l i}=A_{l} / A_{c} ; \rho_{p i}=A_{p} / A_{c}\right) ;$ \\
$\rho_{l} ; \rho_{i} ; \rho_{p}$ & $=$ longitudinal and transversal steel ratios after twisting $\left(\rho_{l}=A_{l} / p_{\mathrm{o}} t_{d} ; \rho_{t}=A_{t} / s t_{d} ; \rho_{p}=A_{p} / p_{\mathrm{o}} t_{d}\right) ;$ \\
$A_{c}$ & $=$ area limited by the outer perimeter $\left(p_{c}\right)$ of the concrete; \\
$p_{\mathrm{o}} ; A_{\mathrm{o}}$ & $=$ perimeter and area limited by the centreline of the shear flow: $A_{\mathrm{o}}=A_{c}-0.5 p_{c} t_{d}+t_{d}^{2}$ and $p_{\mathrm{o}}=p_{c}-4 t_{d} ;$ \\
$v_{12}$ & $=$ modified Hsu/Zhu ratio for torsion: $v_{12}=0.8 \times\left(0.2+850 \varepsilon_{s f}\right)$ if $\varepsilon_{s f} \leq \varepsilon_{y}$ or $v_{12}=0.8 \times 1.9$ if $\varepsilon_{s f}>\varepsilon_{y} ;$ \\
$\varepsilon_{s f} ; \varepsilon_{y}$ & $=$ strain of the mild steel bars that yield first and yielding strain of the mild steel bars.
\end{tabular}

Table 2. $\sigma-\varepsilon$ relationship for concrete in compression for PC beams (for RC beams: $\bar{\varepsilon}_{l i}=0$ )

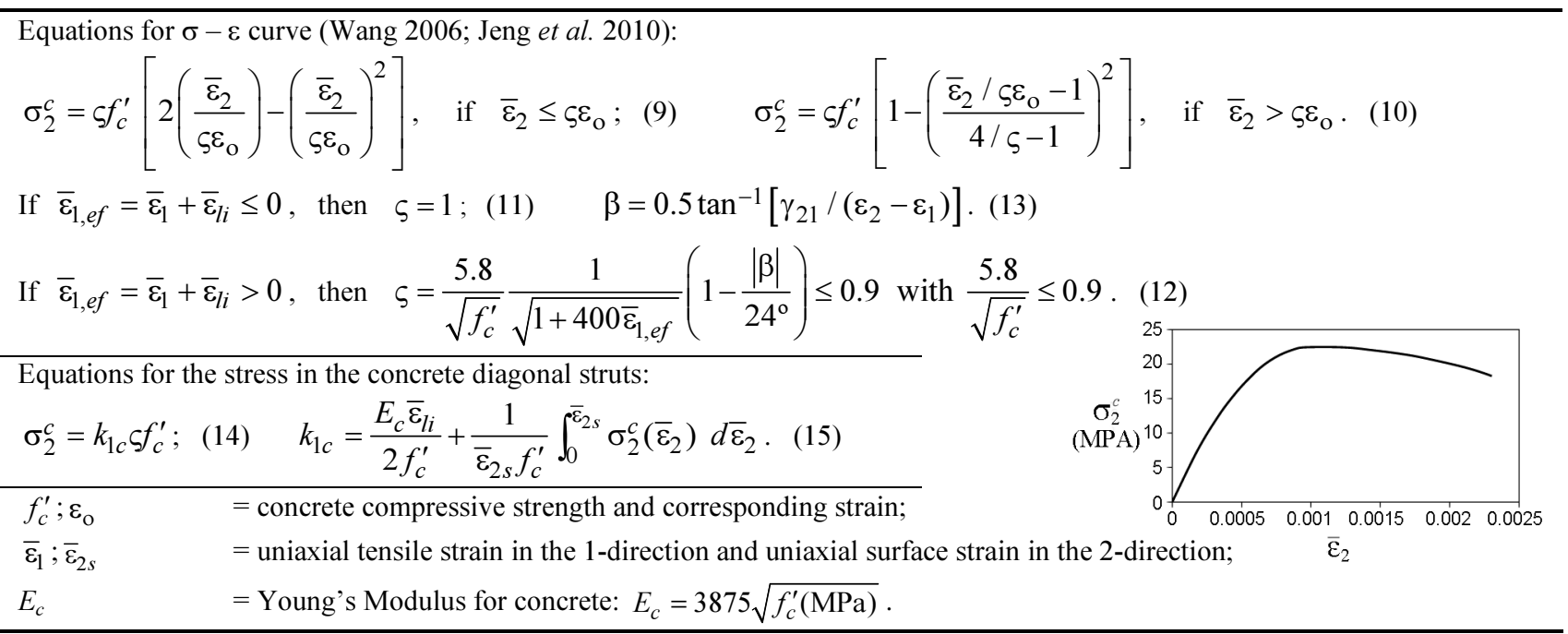


Table 3. $\sigma-\varepsilon$ relationship for concrete in tension for PC beams (for RC beams: $\bar{\varepsilon}_{d e c}=\bar{\varepsilon}_{l i}=0$ )

$$
\begin{aligned}
& \text { Equations for } \sigma-\varepsilon \text { curve (Belarbi, Hsu 1994; Jeng, Hsu 2009; Jeng et al. 2010): } \\
& \sigma_{1}^{c}=E_{c}^{\prime}\left(\bar{\varepsilon}_{1}-\bar{\varepsilon}_{1 i}\right), \quad \text { if } \quad \bar{\varepsilon}_{1} \leq \bar{\varepsilon}_{d e c} \text {; } \\
& \sigma_{1}^{c}=E_{c}^{\prime \prime}\left(\bar{\varepsilon}_{1}-\bar{\varepsilon}_{d e c}\right) \text {, if } \bar{\varepsilon}_{d e c}<\bar{\varepsilon}_{1} \leq \varepsilon_{c r} \text {; } \\
& \sigma_{1}^{c}=f_{c r}\left(\frac{\varepsilon_{c r}}{\bar{\varepsilon}_{1}}\right)^{0.4}, \text { if } \bar{\varepsilon}_{1}>\varepsilon_{c r} \text {; } \\
& E_{c}^{\prime}=2 \frac{f_{c}^{\prime}}{\varepsilon_{\mathrm{o}}} \\
& \bar{\varepsilon}_{d e c}=\bar{\varepsilon}_{l i}-\frac{\sigma_{c i}}{2 E_{c}^{\prime}} ; \\
& E_{c}^{\prime \prime}=\frac{f_{c r}}{\varepsilon_{c r}-\bar{\varepsilon}_{d e c}} ; \\
& f_{c r}=E_{c} \varepsilon_{c r}=1.45 \times 3875 \sqrt{f_{c}^{\prime}(\mathrm{MPa})} \text {. }
\end{aligned}
$$

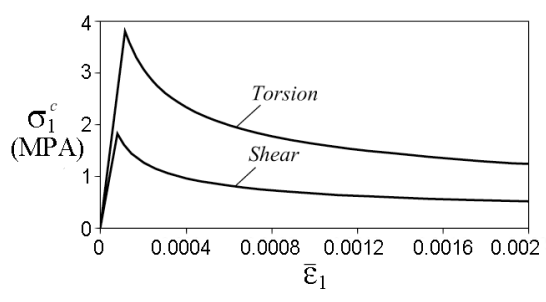

Equations for the stress in the concrete ties:

$\sigma_{1}^{c}=\frac{1}{2}\left(E_{c}^{\prime} \bar{\varepsilon}_{1 s}+\sigma_{c i}\right), \quad$ if $\quad \bar{\varepsilon}_{1 s}^{\prime}=\bar{\varepsilon}_{1 s}+\bar{\varepsilon}_{l i} \leq \bar{\varepsilon}_{d e c}$

$\sigma_{1}^{c}=\left(\frac{1}{4} \sigma_{c i} t_{1}+\int_{0}^{t_{2}} \sigma_{1}^{c}\left(\bar{\varepsilon}_{1}\right) d \bar{\varepsilon}_{1}\right) / t_{d}, \quad$ if $\quad \bar{\varepsilon}_{1 s}^{\prime}>\bar{\varepsilon}_{d e c}$

$$
t_{1}=\frac{\bar{\varepsilon}_{d e c}-\bar{\varepsilon}_{l i}}{\bar{\varepsilon}_{1 s}} t_{d}
$$

$t_{2}=t_{d}-t_{1}$

For RC elements: $\sigma_{1}^{c}=k_{1 t} f_{c r}$;

(28) $k_{1 t}=\frac{1}{\bar{\varepsilon}_{1 s} f_{c r}} \int_{0}^{\bar{\varepsilon}_{1 s}} \sigma_{1}^{c}\left(\bar{\varepsilon}_{1}\right) d \bar{\varepsilon}_{1}$.

\begin{tabular}{ll}
\hline$f_{c r} ; \varepsilon_{c r}$ & $=$ cracking stress and corresponding strain; \\
$\bar{\varepsilon}_{\text {dec }}$ & $=$ strain in the concrete at decompression stage; \\
$t_{1} ; t_{2}$ & $=$ depth of the compressive and tensile stress diagram in the concrete ties.
\end{tabular}

In this study, the integration of the $\sigma-\varepsilon$ curves will be numerically performed in the calculus procedure.

The SMMT incorporates a rational shear modulus to relate the concrete stress to the shear strain (Eqn (30)).

$$
\tau_{21}^{c}=\frac{\sigma_{1}^{c}-\sigma_{2}^{c}}{2\left(\varepsilon_{1}-\varepsilon_{2}\right)} \gamma_{21}+\frac{\sigma_{c i}}{2} \text {. }
$$

To characterize the mild steel in tension, a smeared tensile $\sigma-\varepsilon$ relationship for steel bars embedded in concrete should be adopted because the smeared tensile stress of concrete is incorporated into the SMMT. The $\sigma-\varepsilon$ relationship from Belarbi, Hsu (1994) was adopted (Eqns (31) to (39) in Table 4).
To characterize the prestressing steel in tension, as discussed by Wang (2006), a tensile $\sigma-\varepsilon$ relationship for bare prestressing strands can be used since that the decreased stress in embedded tendons compared with bare strands is less significant than in embedded mild steel compared with bare steel bars. A $\sigma-\varepsilon$ relationship based on the equation of Ramberg and Osgood (1943) was used (Eqns (40) to (41) in Table 5). Hsu and Mo (1985b) showed that this relationship is adequate for current prestressing steel. The strain in the longitudinal prestressing steel is computed considering the initial stress due to prestressing (Eqns (42) to (44) in Table 5).

Table 4. $\sigma-\varepsilon$ relationship for mild steel for PC beams (for RC beams: $\bar{\varepsilon}_{l i}=0$ )

Equations for $\sigma-\varepsilon$ curve (Belarbi, Hsu 1994; Jeng et al. 2010):
$f_{l}=E_{s} \bar{\varepsilon}_{l s}, \quad$ if $\bar{\varepsilon}_{l s} \leq \bar{\varepsilon}_{n} ; \quad(31)$
$f_{l}=f_{y}\left[(0.91-2 B)+\left(0.02+0.25 B_{l}\right)\left(\frac{\bar{\varepsilon}_{l s}}{\varepsilon_{y}}\right)\right], \quad$ if $\bar{\varepsilon}_{l s}>\bar{\varepsilon}_{n} . \quad(32)$




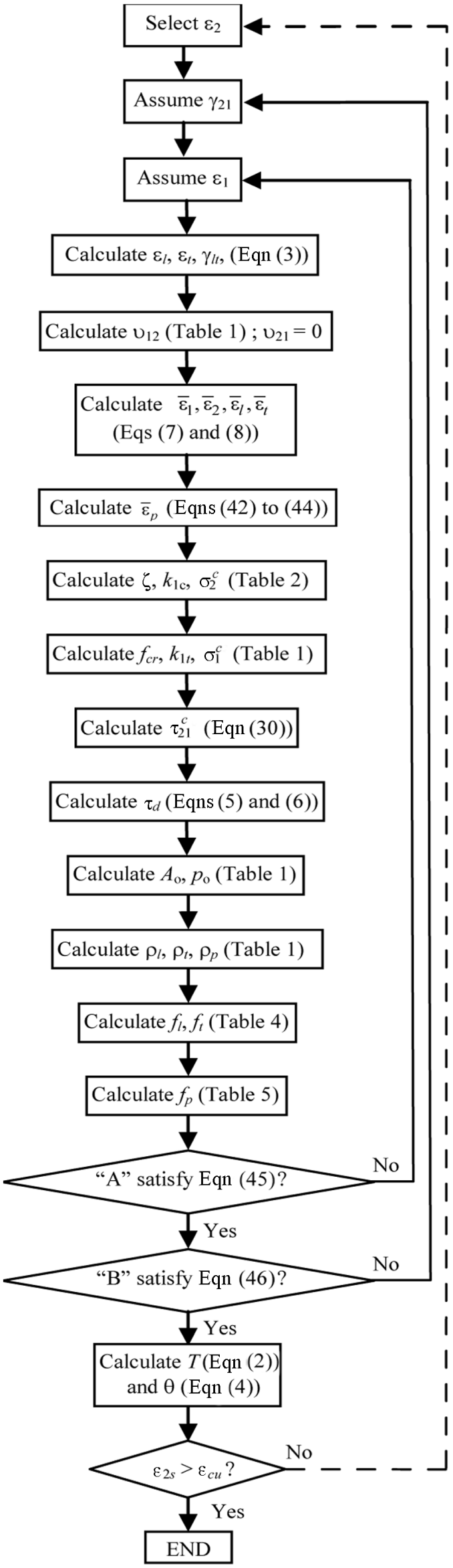

Fig. 1. Flowchart to compute the $T-\theta$ curve
The previous equations lead to the iterative calculus procedure presented in Figure 1 to calculate the theoretical $T-\theta$ curve. The original solution algorithm of the SMMT (Jeng, Hsu 2009) is extended in this article to include PC beams. In the calculus procedure presented in Figure 1 the variables $\varepsilon_{2}, \gamma_{21}$, and $\varepsilon_{1}$ are initially unknown and interdependent.

The convergence criteria are the same as defined by Jeng et al. 2010 for PC beams (Eqns (45) and (46)):

$$
\begin{aligned}
& \underbrace{\rho_{l} f_{l}+\rho_{t} f_{t}+\rho_{p} f_{p}-\rho_{l i} f_{l i}-\rho_{p i} f_{p i}}_{\text {"A" }}=-\left(\sigma_{2}^{c}+\sigma_{1}^{c}-\sigma_{c i}\right) ; \\
& \underbrace{\rho_{l} f_{l}-\rho_{t} f_{t}+\rho_{p} f_{p}-\rho_{l i} f_{l i}-\rho_{p i} f_{p i}}_{\text {"B" }}=-\left(2 \tau_{21}^{c}-\sigma_{c i}\right) .
\end{aligned}
$$

The theoretical ultimate point of the $T-\theta$ curve is defined when $\varepsilon_{2 s}$ reaches its ultimate conventional value $\varepsilon_{c u}$.

\section{3. $T-\theta$ curve}

In general, the $T-\theta$ curves obtained from laboratorial tests on hollow beams (for current reinforcement ratios) under pure torsion up to failure can lead to a typical $T-\theta$ curve, as presented in Figure 2 (Bernardo, Lopes 2009). This curve shows 3 different zones (zone 1, 2 and 3 of Figure 2). The parameters of Figure 2 are: the cracking torque and the corresponding twist $\left(T_{c r}\right.$ and $\left.\theta_{c r}\right)$, the resistance torque and the corresponding twist $\left(T_{r}\right.$ and $\left.\theta_{r}\right)$, the ordinate at the origin for cracked state $\left(T_{\mathrm{o}}^{\mathrm{II}}\right)$, the torsional stiffness in non-cracked and cracked state $\left(K^{\mathrm{I}}\right.$ and $\left.K^{\mathrm{II}}\right)$.

The key points to define the $T-\theta$ curve are defined by their $(\theta ; T)$ coordinates (Figure 2 ).

The key points and properties of $T-\theta$ curve presented in Figure 2 will be used in this study for comparative analysis between experimental and theoretical values (Section 5).

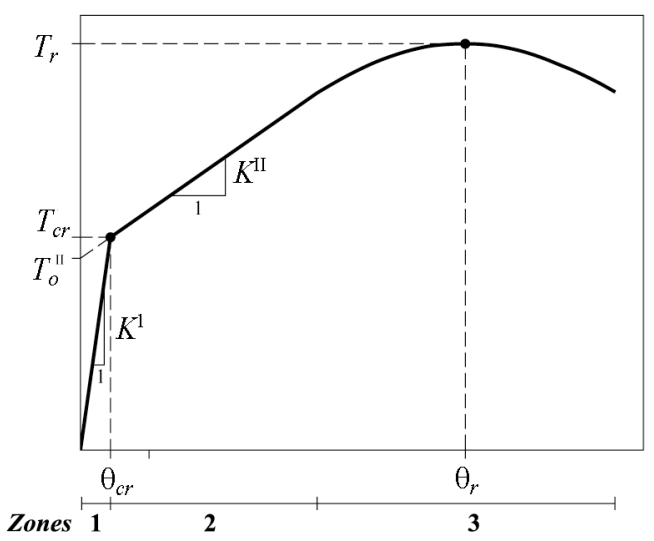

Fig. 2. Typical $T-\theta$ curve

\section{Experimental beams}

The theoretical results obtained from the SMMT will be compared with the results of experimental RC and PC hollow beams under pure torsion which experimental results are available in literature. 
Table 5. $\sigma-\varepsilon$ relationship for prestressing steel

$$
\begin{aligned}
& \text { Equations for } \sigma-\varepsilon \text { curve (Hsu, Mo 1985b): } \\
& f_{p}=E_{p} \varepsilon_{p}, \quad \text { for } \varepsilon_{p} \leq \varepsilon_{p 0.1 \%}=f_{p 0.1 \%} / E_{p} ; \\
& f_{p}=\frac{E_{p} \varepsilon_{p}}{\left[1+\left(\frac{E_{p} \varepsilon_{p}}{f_{p t}}\right)^{4.38}\right]^{\frac{1}{4.38}}}, \text { for } \varepsilon_{p}>\varepsilon_{p 0.1 \%} .
\end{aligned}
$$

Strain in the longitudinal prestressing steel:

$$
\varepsilon_{p}=\varepsilon_{d e c}+\varepsilon_{l} ; \text { (42) } \quad \varepsilon_{d e c}=\varepsilon_{p i}+\varepsilon_{l i} ; \text { (43) } \quad \varepsilon_{p i}=f_{p i} / E_{p} \text {. }
$$

\begin{tabular}{ll}
\hline$E_{p}$ & $=$ \\
$\varepsilon_{p} ; \varepsilon_{p i}$ & $=$ \\
$\varepsilon_{d e c}$ & $=$ \\
$\varepsilon_{l i}$ & $=$
\end{tabular}

= Young's modulus of the prestressing steel;

$=$ strain and initial strain in the prestressing steel;

$=$ strain in the prestressing steel at decompression stage;

\begin{tabular}{|c|c|c|c|c|c|c|c|c|c|c|c|}
\hline Beam & Authors & $\begin{array}{l}x \\
\mathrm{~cm}\end{array}$ & $\begin{array}{l}y \\
\mathrm{~cm}\end{array}$ & $\begin{array}{l}t \\
\mathrm{~cm}\end{array}$ & $\begin{array}{l}x_{1} \\
\mathrm{~cm}\end{array}$ & $\begin{array}{l}y_{1} \\
\mathrm{~cm}\end{array}$ & $\begin{array}{l}A_{s l} \\
\mathrm{~cm}^{2}\end{array}$ & $\begin{array}{l}A_{s t} / \mathrm{s} \\
\mathrm{cm}^{2} / \mathrm{m}\end{array}$ & $\begin{array}{l}f_{c}^{\prime} \\
\mathrm{MPa}\end{array}$ & $\begin{array}{l}f_{l y} \\
\mathrm{MPa}\end{array}$ & $\begin{array}{l}f_{t y} \\
\mathrm{MPa}\end{array}$ \\
\hline D4 & Hsu (1968) & 25.4 & 38.1 & 6.4 & 21.6 & 34.3 & 15.5 & 14.0 & 30.6 & 330 & 333 \\
\hline $\mathrm{T} 2$ & Lampert, Thurlimann (1969) & 50.0 & 50.0 & 8.0 & 44.2 & 44.2 & 18.1 & 10.5 & 25.6 & 357 & 357 \\
\hline $\mathrm{T} 1$ & CEB (1969) & 50.0 & 50.0 & 8.0 & 45.4 & 45.4 & 18.1 & 10.3 & 35.4 & 357 & 357 \\
\hline VH1 & Leonhardt, Schelling (1974) & 32.4 & 32.4 & 6.5 & 28.5 & 28.5 & 3.5 & 2.8 & 17.2 & 447 & 447 \\
\hline $\mathrm{A} 2$ & \multirow{13}{*}{$\begin{array}{l}\text { Bernardo, } \\
\text { Lopes (2009) }\end{array}$} & 60.0 & 60.0 & 10.7 & 53.8 & 53.1 & 14.0 & 6.3 & 47.3 & 672 & 696 \\
\hline A3 & & 60.0 & 60.0 & 10.9 & 54.0 & 53.5 & 18.1 & 8.3 & 46.2 & 672 & 715 \\
\hline A4 & & 60.0 & 60.0 & 10.4 & 52.0 & 52.5 & 23.8 & 11.2 & 54.8 & 724 & 715 \\
\hline A5 & & 60.0 & 60.0 & 10.4 & $\begin{array}{l}52.8 \\
\end{array}$ & 52.8 & $\begin{array}{l}30.7 \\
\end{array}$ & 14.1 & 53.1 & 724 & 672 \\
\hline B2 & & 60.0 & 60.0 & 10.8 & 53.3 & 53.4 & 14.6 & 6.7 & 69.8 & 672 & 696 \\
\hline B3 & & 60.0 & 60.0 & 10.9 & 53.5 & 53.7 & 23.8 & 11.2 & 77.8 & 724 & 715 \\
\hline B4 & & 60.0 & 60.0 & 11.2 & 52.3 & 53.6 & 32.2 & 15.1 & 79.8 & 724 & 672 \\
\hline B5 & & 60.0 & 60.0 & 11.7 & $\begin{array}{l}51.8 \\
\end{array}$ & $\begin{array}{l}51.8 \\
\end{array}$ & 40.2 & 18.9 & 76.4 & 724 & 672 \\
\hline $\mathrm{C} 2$ & & 60.0 & 60.0 & 10.0 & 53.2 & 53.3 & 14.0 & 6.3 & 94.8 & 672 & 696 \\
\hline C3 & & 60.0 & 60.0 & 10.3 & 54.5 & 54.0 & 23.8 & 10.5 & 91.6 & 724 & 715 \\
\hline $\mathrm{C} 4$ & & 60.0 & 60.0 & 10.3 & 54.6 & 54.5 & 30.7 & 14.1 & 91.4 & 724 & 672 \\
\hline $\mathrm{C5}$ & & 60.0 & 60.0 & 10.4 & 54.0 & 54.3 & $\begin{array}{l}6.7 \\
\end{array}$ & 17.4 & 96.7 & 672 & 672 \\
\hline C6 & & 60.0 & 60.0 & 10.4 & 53.3 & 52.9 & 48.3 & 22.6 & 87.5 & 724 & 724 \\
\hline
\end{tabular}

$=$ initial compressive strain in the longitudinal steel;

$f_{p 0.1 \%} ; \varepsilon_{p 0.1 \%}$

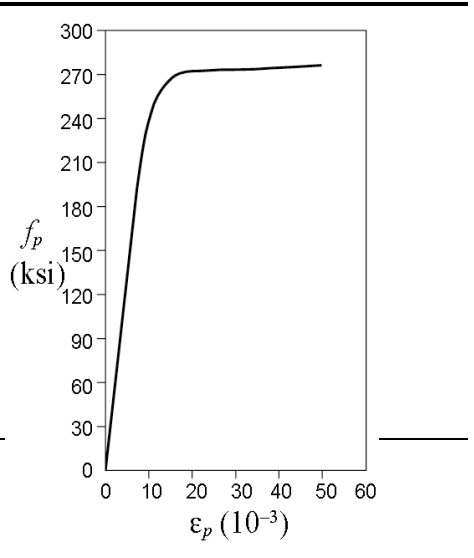

$=$ conventional stress of the longitudinal prestressing steel and corresponding strain.

Table 6. Properties of experimental RC hollow beams

The same hollow beams from Bernardo and Lopes (2008, 2011b) will be used for the comparative analysis. The experimental results of such beams can be considered trustworthy for comparative analysis with global theoretical results, as justified by the referred authors. In fact, not all the experimental results available in literature can be used due to various reasons. For instance, some older studies have not sufficient dates or do not meet basic design recommendations from codes of practice. In this earlier situation, such beams show atypical behaviours under torsion. In other experimental studies the authors present an average medium twists for all the beam length, and not the twists of the critical section. Theoretical twists, based on a cross section analysis, cannot be compared with these experimental twists, mainly if the beams are slender. A more detailed discussion about these aspects can be found in Bernardo and Lopes (2008).

Tables 6 and 7 summarize the geometrical and mechanical properties of $17 \mathrm{RC}$ hollow beams and $3 \mathrm{PC}$ hollow beams found in literature, including the external width $(x)$ and height $(y)$ of the rectangular cross hollow sections, the thickness of the walls $(t)$, the distances between centrelines of legs of the closed stirrups ( $x_{1}$ and $\left.y_{1}\right)$, the total area of longitudinal reinforcement $\left(A_{s l}\right)$, the distributed area of one leg of the transversal reinforcement $\left(A_{s t} / s\right.$, where $s$ is the spacing of transversal reinforcement), the average concrete compressive strength $\left(f_{c}^{\prime}\right)$ and the average yielding stress of longitudinal and transversal reinforcement $\left(f_{l y}\right.$ and $\left.f_{t y}\right)$. For PC beams, Table 7 summarizes information about prestressing, namely: the total area of longitudinal prestress reinforcement $\left(A_{p}\right)$, the proportional conventional limit stress to $0.1 \%\left(f_{p 0,1 \%}\right)$, the initial stress in the prestressing reinforcement $\left(f_{p i}\right)$ and the average stress in the concrete due to prestressing $\left(f_{c p}\right)$.

For each beam, parameters $\varepsilon_{0}$ and $\varepsilon_{c u}$ were computed from NP EN 1992-1-1 (2010).

\section{Comparative analyses with experimental beams}

The calculus procedure from Section 2 was implemented with programming language DELPHI. This computer tool allows the calculation of the full theoretical $T-\theta$ curve of RC and PC beams under torsion. 
Table 7. Properties of experimental PC hollow beams

\begin{tabular}{|c|c|c|c|c|c|c|c|c|c|c|c|c|c|c|c|}
\hline Beam & Authors & $\begin{array}{c}x \\
\mathrm{~cm} \\
\end{array}$ & $\begin{array}{c}y \\
\mathrm{~cm}\end{array}$ & $\begin{array}{c}t \\
\mathrm{~cm} \\
\end{array}$ & $\begin{array}{l}x_{1} \\
\mathrm{~cm} \\
\end{array}$ & $\begin{array}{l}y_{1} \\
\mathrm{~cm}\end{array}$ & $\begin{array}{l}A_{s l} \\
\mathrm{~cm}^{2} \\
\end{array}$ & $\begin{array}{l}A_{s t} / \mathrm{s} \\
\mathrm{cm}^{2} / \mathrm{m} \\
\end{array}$ & $\begin{array}{c}A_{p} \\
\mathrm{~cm}^{2}\end{array}$ & $\begin{array}{c}f_{c}^{\prime} \\
\mathrm{MPa} \\
\end{array}$ & $\begin{array}{c}f_{l y} \\
\mathrm{MPa} \\
\end{array}$ & $\begin{array}{c}f_{t y} \\
\mathrm{MPa} \\
\end{array}$ & $\begin{array}{c}f_{p 0,1 \%} \\
\text { (MPa) }\end{array}$ & $\begin{array}{c}f_{p i} \\
\text { (MPa) } \\
\end{array}$ & $\begin{array}{c}f_{c p} \\
(\mathrm{MPa}) \\
\end{array}$ \\
\hline $\mathrm{P} 2$ & itchell, Collins (1974) & 35.6 & 43.1 & 8.9 & 31.2 & 38.9 & 5.7 & 7.4 & 5.7 & 32.9 & 407 & 407 & 1476 & 1145 & 4.89 \\
\hline D1 & Bernardo, & 60.0 & 60.0 & 11.4 & 54.3 & 54.2 & 23.8 & 11.2 & 23.8 & \begin{tabular}{|l|}
80.8 \\
\end{tabular} & 724 & 715 & 1670 & 640 & 1.79 \\
\hline $\mathrm{D} 2$ & Lopes (2009) & 60.0 & 60.0 & 11.5 & 55.5 & 55.5 & 23.8 & 11.2 & 23.8 & 58.8 & 724 & 715 & 1670 & 1100 & 3.08 \\
\hline
\end{tabular}

\subsection{Parametric analysis}

Since only 3 PC beams were considered, the comparative analysis based on parametric analysis to check the SMMT will be carried out only for RC beams.

\subsubsection{Zone 1}

Table 8 presents, for all the experimental RC hollow beams, the experimental and theoretical values for the cracking torque $\left(T_{c r, \exp }\right.$ and $\left.T_{c r, t h}\right)$, the corresponding twists $\left(\theta_{c r, \text { exp }}\right.$ and $\left.\theta_{c r, t h}\right)$ and the experimental torsional stiffness in non-cracked state $\left(K_{\text {exp }}^{\mathrm{I}}\right)$. The ratios between experimental and theoretical values are also presented in Table 8 , as well as the average value $\bar{x}$, the sample standard deviation $s$ and the coefficient of variation $c v$. Since the correction (increasing $45 \%$ ) proposed by Jeng and Hsu (2009) for pre-cracking stiffness $\left(E_{c}\right)$ and for the strain at peak stress $\left(\varepsilon_{c r}\right)$ was only validated for solid sections, the theoretical values were calculated with $(\times 1.45)$ and without the correction factor $(\times 1)$. Only values for $T_{c r}$ and $\theta_{c r}$ are presented since the correction mainly affects the pre-cracking stage and $K^{\mathrm{I}}$ is computed from $T_{c r} / \theta_{c r}$ (secant stiffness).

Table 8 shows that if no correction is made for $\varepsilon_{c r}$ and $E_{c}$ (considering the values for shear), the theoretical cracking torques are underestimated $(\bar{x}=1.44$, with an acceptable value for $c v=9.8 \%$ ), as also previously observed for solid sections (Jeng, Hsu 2009). However, with the same correction proposed by Jeng and Hsu (2009) for solid sections $(\times 1.45)$, Table 8 shows that the theoretical cracking torques are overestimated $(\bar{x}=0.67$, with $c v=$ 9.9\%).

For the twists, the high values for the coefficient of variation $(c v>>10 \%)$ do not allow to establish solid conclusions based on the average value. This variability could be probably attributed to the very low values of the twists on pre-cracking state, which certainly led to a larger variability of the experimental twist due to the limitation of the accuracy of the rotation transducers.

Jeng and Hsu (2009) previously explained that the need for the correction $(\times 1.45)$ could be attributed to the strain gradient effect due to the bending of concrete struts. This effect cannot be considered the unique explanation to justify the increase by $45 \%$ of $E_{c}$ and $\varepsilon_{c r}$ for solid sections, because the results from Table 8 show that for hollow sections such increase should be lower. The reason of the differences observed between solid and hollow sections can probably be attributed to the influence, in the pre-cracking state, of the concrete core in solid sections. In fact, SMMT don't incorporate such influence. In the pre-cracking state, concrete core increases the torsional stiffness of the solid beams.

Table 8. Comparative analysis for Zone 1

\begin{tabular}{|c|c|c|c|c|c|c|c|c|c|c|c|c|c|c|c|c|c|}
\hline \multirow{2}{*}{\multicolumn{4}{|c|}{$\mathrm{kNm} \times 10^{-3} \quad \mathrm{kNm} / \mathrm{Rad}$}} & \multirow{2}{*}{\multicolumn{4}{|c|}{$\times 1$ (no correction) }} & \multirow{2}{*}{\multicolumn{4}{|c|}{$\times 1.45$ (solid sections) }} & \multirow{2}{*}{\multicolumn{6}{|c|}{$\times 1.24$ (proposal for hollow sections) }} \\
\hline & & & & & & & & & & & & & & & & & \\
\hline Beam & $T_{c r, \exp }$ & $\theta_{c r, \exp }$ & $K_{e x p}^{\mathrm{I}}$ & $T_{c r, t h}$ & $\theta_{c r, t h}$ & $\frac{T_{c r, e x p}}{T_{c r, t h}}$ & $\frac{\theta_{c r, \exp }}{\theta_{c r, t h}}$ & $T_{c r, t h}$ & $\theta_{c r, t h}$ & $\frac{T_{c r, e x p}}{T_{c r, t h}}$ & $\frac{\theta_{c r, \text { exp }}}{\theta_{c r, t h}}$ & $T_{c r, t h}$ & $\theta_{c r, t h}$ & $K_{t h}^{\mathrm{I}}$ & $\frac{T_{c r, e x p}}{T_{c r, t h}}$ & $\frac{\theta_{c r, \exp }}{\theta_{c r, t h}}$ & $\frac{K_{e x p}^{1}}{K_{t h}^{1}}$ \\
\hline D4 & .02 & 2.06 & & 11.21 & 3.25 & 1.41 & 0.63 & 0.57 & 2.70 & 0.77 & 0.10 & 4.14 & 3.40 & & 1.12 & 0.61 & 1.85 \\
\hline $\mathrm{T} 2$ & 6.67 & 1.03 & & 33.78 & 2.10 & 1.38 & 0.49 & 66.93 & 1.76 & 0.70 & 58 & 5.11 & 1.53 & 4.8 & .03 & 67 & 1.54 \\
\hline $\mathrm{T} 1$ & 47.99 & 0.75 & & 38.03 & 1.33 & 1.26 & 0.57 & 78.13 & 1.45 & 0.61 & & 1.83 & 1.08 & & & 69 & 1.33 \\
\hline VH1 & 11.99 & 2.15 & 85.6 & 7.10 & 1.88 & 1.69 & 1.14 & 14.66 & 3.52 & 0.82 & 0.61 & 10.26 & 1.17 & 5585.6 & 1.17 & 1.84 & 0.64 \\
\hline $\mathrm{A} 2$ & 9.50 & 1.17 & & 62.56 & 0.33 & 1.75 & 3.57 & 144.77 & 0.66 & 0.76 & 78 & 103.12 & 0.59 & 5.0 & .06 & 9 & 0.56 \\
\hline $\mathrm{A} 3$ & & 0.99 & & & & & & & & & & & & & & & .64 \\
\hline $\mathrm{A} 4$ & 120.87 & 1.10 & 109929.7 & 84.73 & 0.78 & 1.43 & 1.42 & 174.78 & 1.09 & 0.69 & 1.01 & 111.50 & 0.61 & 109929.7 & 1.08 & 1.81 & 0.60 \\
\hline A5 & 0.93 & 0.77 & 476.1 & 74.51 & 0.62 & 1.62 & 1.24 & 171.79 & 0.95 & 0.70 & 0.81 & 108.75 & 0.58 & 157476.1 & 1.11 & 1.32 & 0.84 \\
\hline B2 & & 0.77 & & & 0.35 & & & & & & & & & & & & .59 \\
\hline B3 & 0.45 & 0.75 & 166095.4 & 88.57 & 0.36 & 1.47 & 2.11 & 204.44 & 0.76 & 0.64 & 0.99 & 129.41 & 1.04 & 166095.4 & 1.01 & 0.73 & 1.33 \\
\hline B4 & 142.93 & 1.22 & 989.8 & 95.10 & 0.91 & 1.50 & 1.35 & 210.85 & 0.77 & 0.68 & 1.59 & 145.53 & 0.89 & 116989.8 & 0.98 & 1.37 & 0.72 \\
\hline B5 & 146.26 & 1.12 & 5.2 & 102.31 & 0.79 & 1.43 & 1.41 & 210.58 & 1.50 & 0.69 & & 125.77 & 1.42 & & .16 & 78 & 1.48 \\
\hline $\mathrm{C} 2$ & 124.46 & 0.86 & 145526.6 & 99.49 & 0.40 & 1.25 & 2.17 & 198.01 & 0.60 & 0.63 & 1.42 & 132.60 & 0.46 & 145526.6 & 0.94 & 1.84 & 0.51 \\
\hline $\mathrm{C} 3$ & 1.94 & 1.12 & 118114.4 & 96.80 & 0.38 & 1.36 & 2.98 & 221.81 & 0.90 & 0.59 & 1.24 & 129.24 & 0.45 & 118114.4 & 1.02 & 2.49 & 0.41 \\
\hline $\mathrm{C} 4$ & 132.60 & 0.89 & 148973.5 & 96.64 & 0.37 & 1.37 & 2.39 & 221.78 & 0.87 & 0.60 & 1.02 & 129.09 & 0.45 & 3.5 & 1.03 & 99 & 0.52 \\
\hline $\mathrm{C} 5$ & 8.34 & 0.89 & 155417.6 & 101.99 & 0.38 & 1.36 & 2.33 & 232.74 & 0.95 & 0.59 & 0.94 & 142.80 & 1.11 & 155417.6 & 0.97 & 0.80 & 1.20 \\
\hline C6 & 139.09 & 0.94 & 147580.1 & 110.72 & 0.79 & 1.26 & 1.19 & 224.76 & 1.50 & 0.62 & 0.63 & 148.06 & 0.74 & 147580.1 & 0.94 & 1.28 & 0.74 \\
\hline & & & & & $\bar{x}$ & 1.44 & 1.68 & & $\bar{x}$ & 0.67 & 0.99 & & & $\bar{x}$ & 1.04 & 1.40 & 0.91 \\
\hline & & & & & 3 & 0.14 & 0.85 & & $s$ & 0.07 & 0.36 & & & $s$ & 0.08 & 0.59 & 0.44 \\
\hline & & & & & $c v$ & $9.8 \%$ & $51.0 \%$ & & $c v$ & $9.9 \%$ & $36.4 \%$ & & & $c v$ & $7.3 \%$ & $42.2 \%$ & $48.7 \%$ \\
\hline
\end{tabular}


Figure 3 illustrates the earlier observations related with $T_{c r}$ for Beam A2 (chosen as an example). Figure 2 also confirms that for pre-cracking state the twists are very small and no notable differences are observed between the torsional stiffness values. From the previous observation, it can be state that the correction factor for hollow sections should be lower than the one proposed by Jeng and Hsu (2009) for solid section.

By conducting a parametric study with all the experimental cracking torques and twists, a new correction factor $(\times 1.24)$ is proposed for hollow sections. Then, the pre-cracking stiffness and the strain at peak stress will be increased by $24 \%$ for hollow sections. New theoretically values with this correction $(\times 1.24)$ are presented in Table 8. This table shows that the new estimations for the theoretical cracking torques are very good $(\bar{x}=1.04$, with a lower value for $c v=7.3 \%$ ). However, a high value for the coefficient of variation $(c v>>10 \%)$ still exists for the twist and the torsional stiffness (related with the twist). Since the deformations in pre-cracking state are very low the less positive results for the twists can be considered not very important.

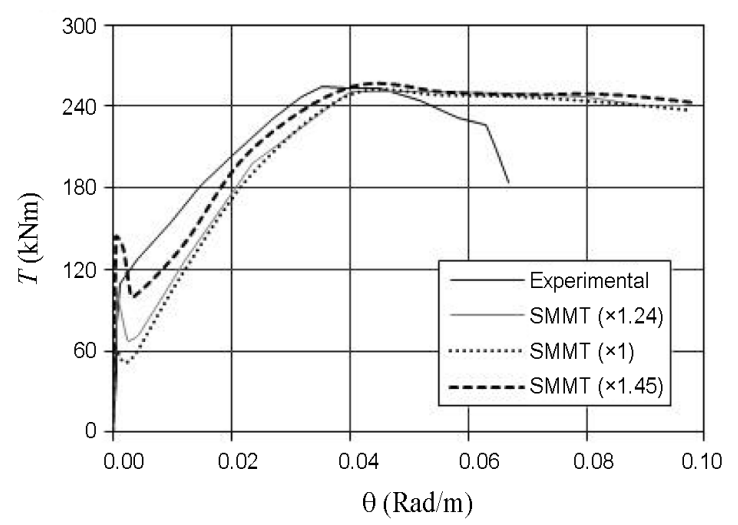

Fig. 3. $T-\theta$ curves for Beam A2

Figure 3 illustrates the positive change for $T_{c r}$ in $T-$ $\theta$ curve for Beam A2 due to the proposed correction ( $\times 1.24)$. The sudden "fall" of the theoretical $T-\theta$ curve after cracking is also generally observed for solid sections (Jeng, Hsu 2009). This aspect will be commented in the final section. Figure 3 also shows that the correction of $E_{c}$ and $\varepsilon_{c r}$ has no notable effect on the maximum torque.

\subsubsection{Zone 2}

Table 9 summarizes the results for the torsional stiffness in cracked state $\left(K^{\mathrm{II}}\right)$ and for the ordinate at the origin $\left(T_{\mathrm{o}}^{\mathrm{II}}\right)$ of the straight line that represents approximately the $T-\theta$ curve in cracked state (Figure 2). Parameters $K^{\mathrm{II}}$ and $T_{\mathrm{o}}^{\mathrm{II}}$ were obtained approximately by calculating a straight line by linear regression of the theoretical and experimental $T-\theta$ curve points corresponding to Zone 2 (Figure 2). Only the points located along the $T-\theta$ curve with an approximately straight development were considered. While parameter $K^{\mathrm{II}}$ measures the slope of the $T$ $\theta$ curve in the Zone 2, parameter $T_{0}^{\text {II }}$ (Figure 2) measure the "position" of the $T-\theta$ curve in the graph. Table 9 presents, for each experimental beam, the experimental values ( $K_{\exp }^{\mathrm{II}}$ and $T_{\mathrm{o} \text {,exp }}^{\mathrm{II}}$ ) and the correspondent theoretical values ( $K_{t h}^{\mathrm{II}}$ and $T_{\mathrm{o} \text {,th }}^{\mathrm{II}}$ ) of the parameters under study. Theoretical parameters were computed with the proposed correction for pre-cracking state and justified in Section $5.1 .1(\times 1.24)$. The ratios between experimental and theoretical values are also presented in Table 9, as well as $\bar{x}$, $s$ and $c v$ values.

Table 9 shows that the theoretical values for the torsional stiffness in cracked state are acceptable, although a bit overestimated $(\bar{x}=0.91$, with a value for $c v=$ $14.1 \%)$. For the ordinate at the origin the high values for the coefficient of variation ( $c v>>10 \%$ ) do not allow to establish solid conclusions based on the average value. Nevertheless, it can be state that this parameter is broadly underestimated for the majority of the beams. This last observation could be related to the sudden "fall" of the theoretical $T-\theta$ curve after cracking. This aspect will be commented in the Conclusions section.

Table 9. Comparative analysis for Zone 2

\begin{tabular}{|c|c|c|c|c|c|c|}
\hline & $\mathrm{kNm} / \mathrm{Rad}$ & $\mathrm{kNm}$ & \multicolumn{4}{|c|}{$\times 1.24$ (hollow sections) } \\
\hline Beam & $K_{e x p}^{\mathrm{II}}$ & $T_{\text {o,exp }}^{\mathrm{II}}$ & $K_{t h}^{\mathrm{II}}$ & $T_{\mathrm{o}, \mathrm{th}}^{\mathrm{II}}$ & $\frac{K_{e p}^{\|}}{K_{t h}^{\| \prime}}$ & $\frac{T_{o, e p}^{\mathrm{N}}}{T_{o, t h}^{\mathrm{N}}}$ \\
\hline D4 & 864.9 & 15.67 & 821.3 & 3.77 & 1.05 & 1.14 \\
\hline T2 & 93.3 & 30.07 & 4533.2 & 31.50 & 0.99 & 0.95 \\
\hline $\mathrm{T} 1$ & 60. & 29.78 & 4924.5 & 32.94 & 0.91 & 0.90 \\
\hline VH1 & 3. & 11.36 & 388.2 & 5.41 & 0.55 & 2.10 \\
\hline $\mathrm{A} 2$ & 4304.1 & 111.34 & 5021.4 & 61.19 & 0.86 & 1.82 \\
\hline $\mathrm{A} 3$ & 5715,4 & 12.90 & 7239.0 & 58.31 & 0.79 & 1.94 \\
\hline A4 & 7311 & 0.56 & 7612.1 & 86.45 & 0.96 & 1.39 \\
\hline A5 & 8087.0 & 133.57 & 12307.0 & 67.57 & 0.66 & 1.98 \\
\hline $\mathrm{B} 2$ & & 68 & 7187.7 & 49.49 & 0.71 & 2.36 \\
\hline B3 & & 6.51 & 9738.5 & 76.99 & 0.80 & 1.64 \\
\hline B4 & 11491.0 & 20.54 & 9884.2 & 117.22 & 1.16 & 1.03 \\
\hline B5 & 12766.0 & 32.41 & 13766.0 & 100.64 & 0.93 & 1.32 \\
\hline C2 & 5072.5 & 124.55 & 7610.5 & 46.04 & 0.67 & 2.71 \\
\hline $\mathrm{C} 3$ & 8352.6 & 124.03 & 9796.0 & 77.35 & 0.85 & 1.60 \\
\hline $\mathrm{C} 4$ & 11360.0 & 125.65 & 10947.0 & 85.58 & 1.04 & 1.47 \\
\hline $\mathrm{C} 5$ & 14767.0 & 00.18 & 16040.0 & 83.68 & 0.92 & 1.20 \\
\hline $\mathrm{C6}$ & 16506.0 & 124.98 & 16310.0 & 112.37 & 1.01 & 1.11 \\
\hline & & & & $\bar{x}$ & 0.91 & 1.47 \\
\hline & & & & & 0.13 & 0.52 \\
\hline & & & & & $14.3 \%$ & $35.4 \%$ \\
\hline
\end{tabular}

\subsubsection{Zone 3}

Finally, Table 10 summarizes the results for the resistance torque $\left(T_{r}\right)$ and the corresponding twist $\left(\theta_{r}\right)$.

The results show that the previsions for resistance torque $\left(T_{r}\right)$ are very good. For the correspondent twists $\left(\theta_{r}\right)$ the results show that this parameter is somewhat underestimated but acceptable. This results shows that the correction of the Hsu/Zhu ratio for torsion (Eqn (47), with $\left.\left(\mathrm{v}_{21}\right)_{\text {Torsion }}=0\right)$, as proposed by Jeng and Hsu (2009) for solid sections, remains valid for hollow sections. 


$$
\left(\mathrm{v}_{12}\right)_{\text {Torsion }}=0.8\left(\mathrm{v}_{12}\right)_{\text {Shear }} \text {. }
$$

It should be noted that the pre-cracking $T-\theta$ curve is slightly influenced by the correction of the Hsu/Zhu ratio. This explains why this subject was not previously referred.

Table 10. Comparative analysis for Zone 3

\begin{tabular}{|c|c|c|c|c|c|c|}
\hline & $\mathrm{kNm}$ & $\times 10^{-3} \mathrm{Rad}$ & \multicolumn{4}{|c|}{$\times 1.24$ (hollow sections) } \\
\hline Beam & $T_{r, \exp }$ & $\theta_{r, \exp }$ & $T_{r, t h}$ & $\theta_{r, t h}$ & $\frac{T_{r, \text { eqp }}}{T_{r, \mathrm{~h}}}$ & $\frac{\theta_{r, \text { exp }}}{\theta_{r, t h}}$ \\
\hline $\mathrm{D} 4$ & 47.93 & 51.84 & 49.74 & 52.62 & 0.96 & 0.99 \\
\hline$\overline{\mathrm{T} 2}$ & 132.91 & 36.53 & 138.54 & 32.80 & 0.96 & 1.11 \\
\hline $\mathrm{T} 1$ & 140.01 & 40.42 & 142.92 & 40.80 & 0.98 & 0.99 \\
\hline VH1 & 21.79 & 50.00 & 21.64 & 57.41 & 1.01 & 0.87 \\
\hline A2 & 254.08 & 35.24 & 251.38 & 40.00 & 1.01 & 0.88 \\
\hline $\mathrm{A} 3$ & 299.92 & 36.67 & 311.00 & 40.07 & 0.96 & 0.92 \\
\hline A4 & 368.22 & 40.06 & 398.02 & 44.18 & 0.93 & 0.91 \\
\hline A5 & 412.24 & 37.59 & 426.63 & 41.42 & 0.97 & 0.91 \\
\hline B2 & 273.28 & 31.19 & 269.58 & 43.67 & 1.01 & 0.71 \\
\hline B3 & 355.85 & 31.14 & 409.65 & 36.74 & 0.87 & 0.85 \\
\hline B4 & 437.85 & 28.01 & 440.43 & 33.50 & 0.99 & 0.84 \\
\hline B5 & 456.19 & 26.63 & 460.01 & 29.67 & 0.99 & 0.90 \\
\hline $\mathrm{C} 2$ & 266.14 & 32.88 & 259.75 & 46.82 & 1.02 & 0.70 \\
\hline $\mathrm{C} 3$ & 351.17 & 28.66 & 415.76 & 35.33 & 0.84 & 0.81 \\
\hline $\mathrm{C} 4$ & 450.31 & 29.55 & 444.58 & 33.67 & 1.01 & 0.88 \\
\hline $\mathrm{C} 5$ & 467.26 & 27.75 & 460.36 & 28.00 & 1.01 & 0.99 \\
\hline $\mathrm{C} 6$ & 521.33 & 25.41 & 509.31 & 27.20 & 1.02 & 0.93 \\
\hline & & & & $\bar{x}$ & 0.99 & 0.90 \\
\hline & & & & $s$ & 0.05 & 0.10 \\
\hline & & & & $c v$ & $5.3 \%$ & $11.1 \%$ \\
\hline
\end{tabular}

\subsection{Graphical analysis}

Figures 4 to 20 present the $T-\theta$ curves concerning the RC hollow beams analysed throughout this study.

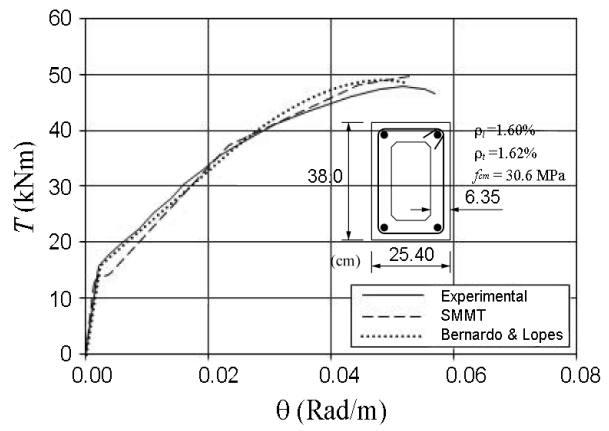

Fig. 4. $T-\theta$ curves for Beam D4

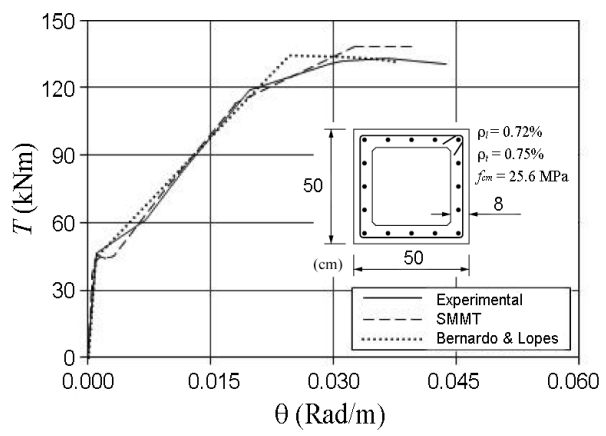

Fig. 5. $T-\theta$ curves for Beam T2
Figures 4 to 20 include the experimental curve and the theoretical curves computed from SMMT with the proposed correction factor for the pre-cracking state $(\times 1.24)$ and also from the global model of Bernardo and Lopes $(2008,2011 b)$ for comparison.

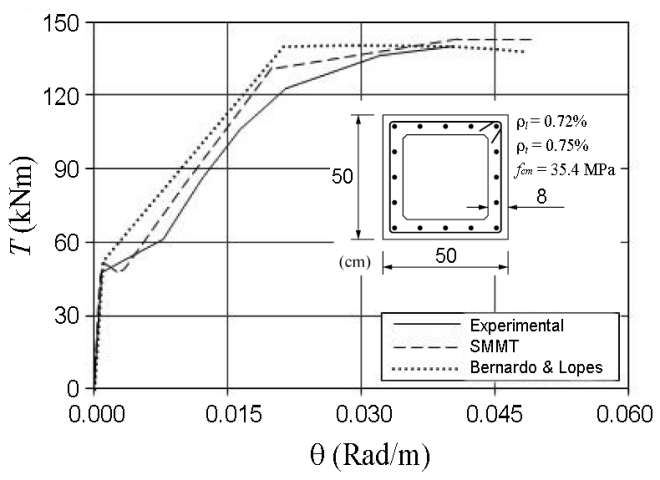

Fig. 6. $T-\theta$ curves for Beam T1

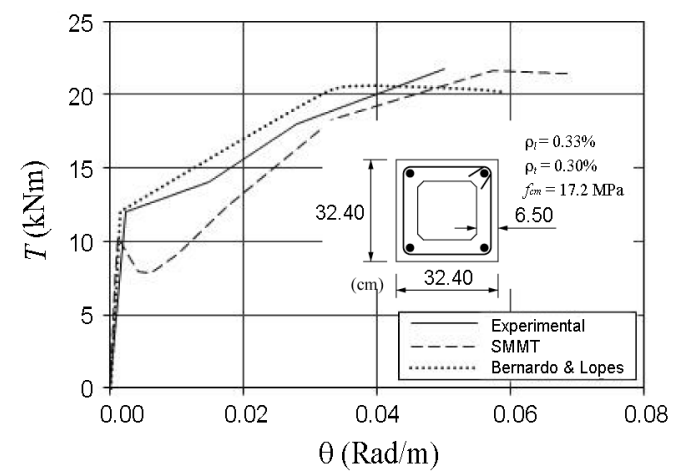

Fig. 7. $T-\theta$ curves for Beam VH1

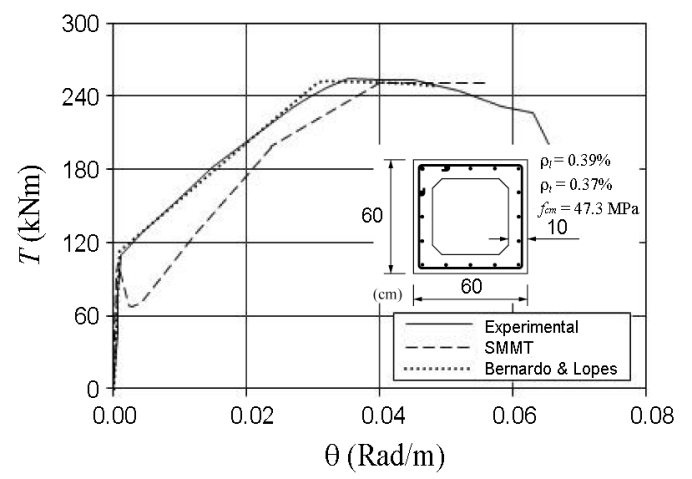

Fig. 8. $T-\theta$ curves for Beam A2

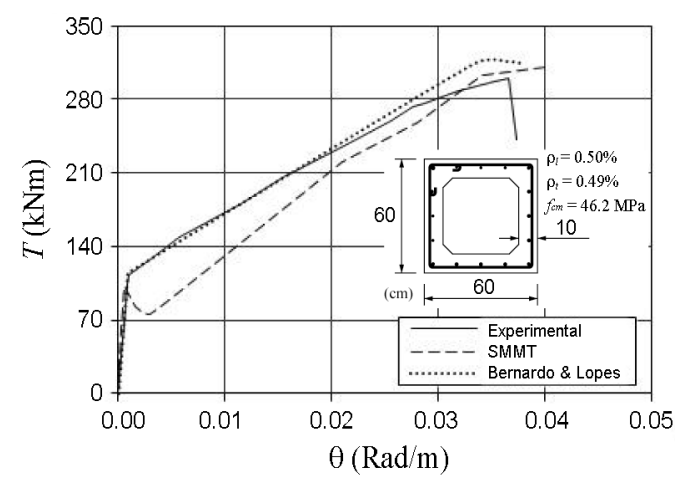

Fig. 9. $T-\theta$ curves for Beam A3 


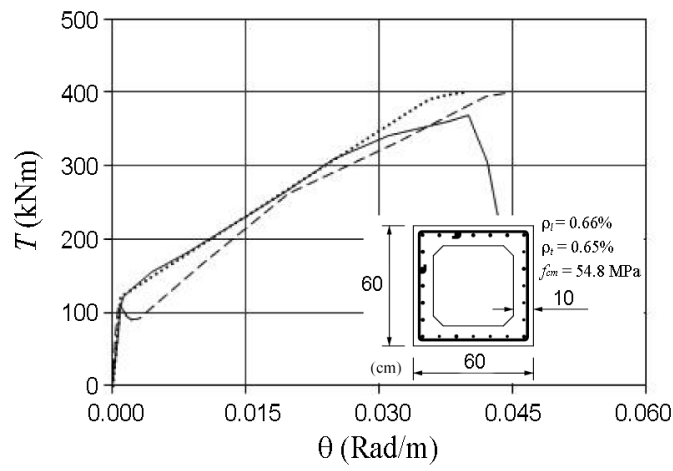

Fig. 10. $T-\theta$ curves for Beam A4

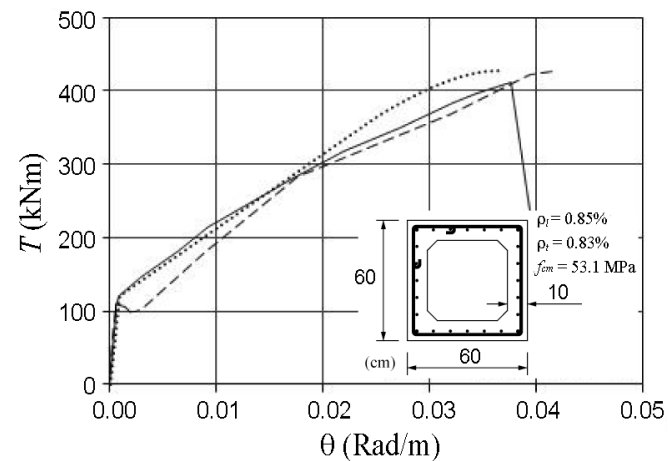

Fig. 11. $T-\theta$ curves for Beam A5

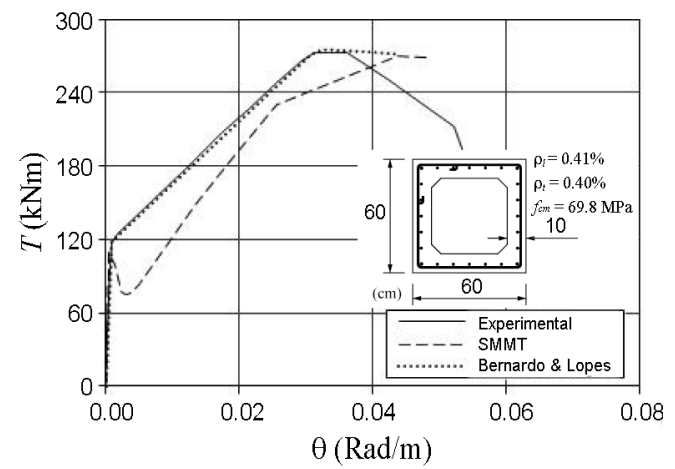

Fig. 12. $T-\theta$ curves for Beam B2

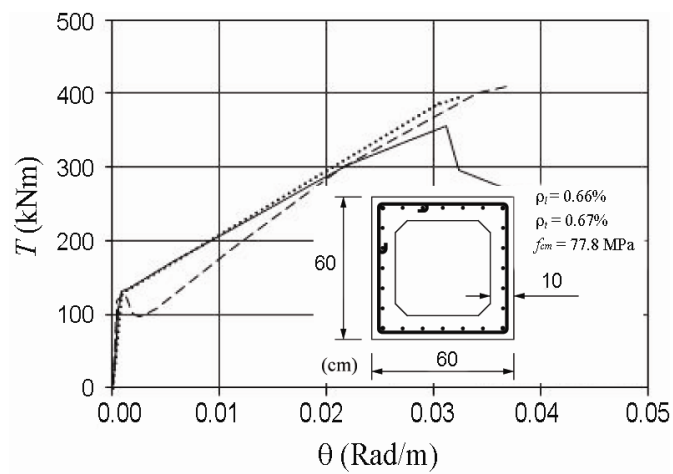

Fig. 13. $T-\theta$ curves for Beam B3

Beams B3 and C3 show relevant deviations from theoretical to experimental values in the final zone of the $T-\theta$ curves. Such deviations are due to the somehow premature failure of such beams by breaking off of concrete at the corners (Bernardo, Lopes 2008).

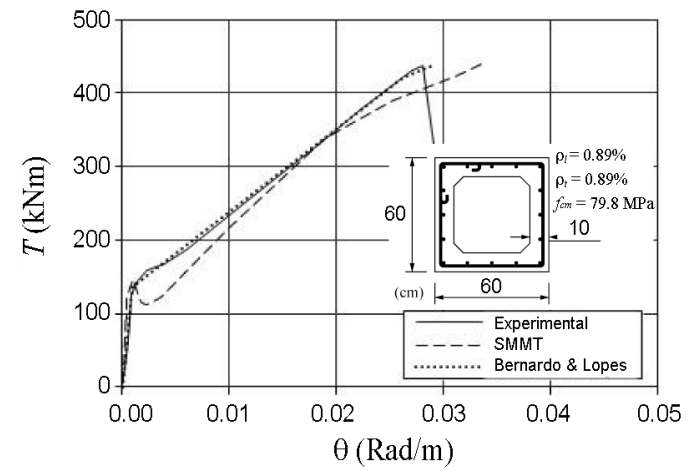

Fig. 14. $T-\theta$ curves for Beam B4

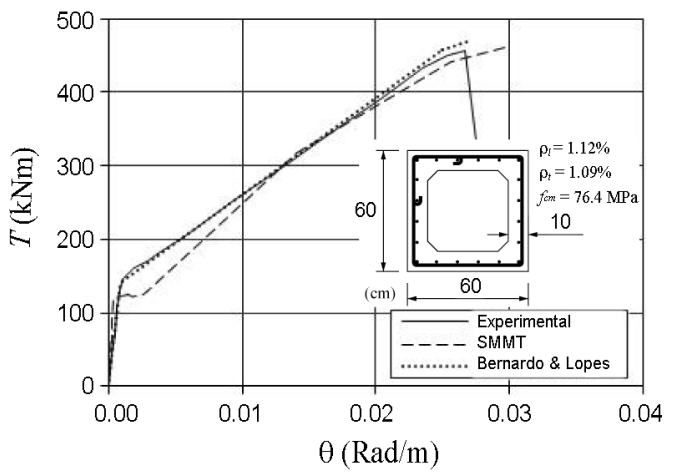

Fig. 15. $T-\theta$ curves for Beam B5

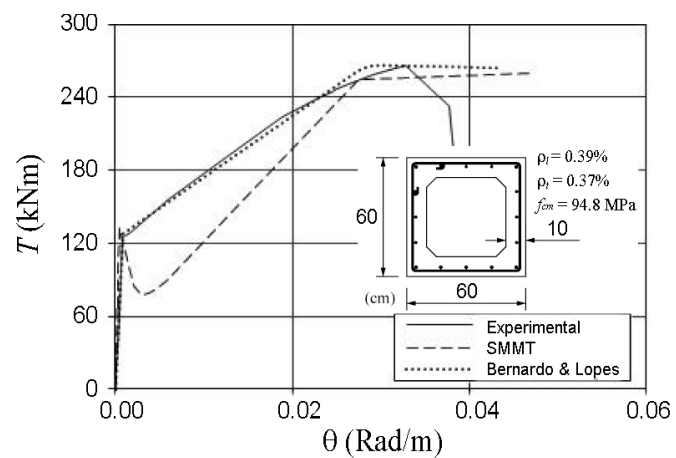

Fig. 16. $T-\theta$ curves for Beam $\mathrm{C} 2$

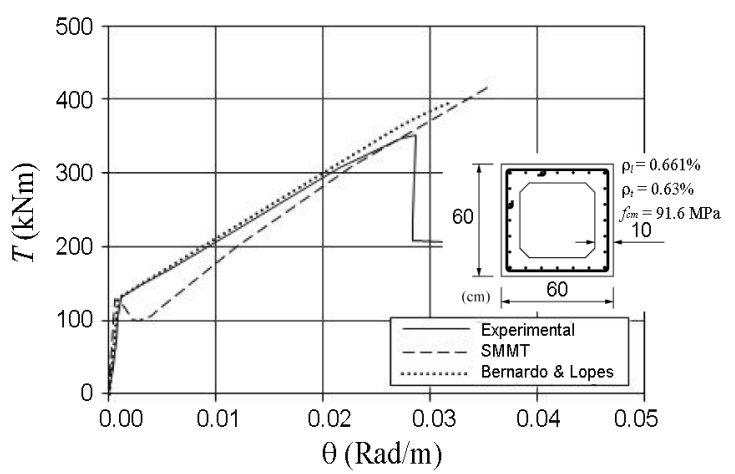

Fig. 17. $T-\theta$ curves for Beam $\mathrm{C} 3$

In general, Figures 4 to 20 confirm the conclusions obtained and based on the parametric analysis (Section 5.1). The SMMT model shows some difficulty to predict the cracking state of the beams (Zone 2 of Figure 2) due to the theoretical sudden "fall" of the $T-\theta$ curve after the cracking torque is reached (probably related with the 
shape of the constitutive relationship for concrete in tension). This is particularly true for beams with lower reinforcement ratio. Such behaviour is not experimentally observed either for solid sections (Jeng, Hsu 2009) or for hollow sections (Bernardo, Lopes 2009). This shows that SMMT should be improved in order to solve this problem. Probably new and realistic relationships for concrete in tension for beams under torsion should be studied.

Figures 4 to 20 also show that the theoretical curves from the global model of Bernardo and Lopes (2008, $2011 \mathrm{~b}$ ) are closer to the experimental ones. However, it should be pointed that SMMT constitutes a more rational model since is based on a single theory.

Figures 21 to 23 present the $T-\theta$ curves concerning the PC hollow beams (Table 7). Theoretical curves from SMMT where computed with the same correction for precracking state as for RC beams.

Figures 21 to 23 show some large deviations between the $T-\theta$ curve from SMMT and the other ones. No solid conclusions can be established because only 3

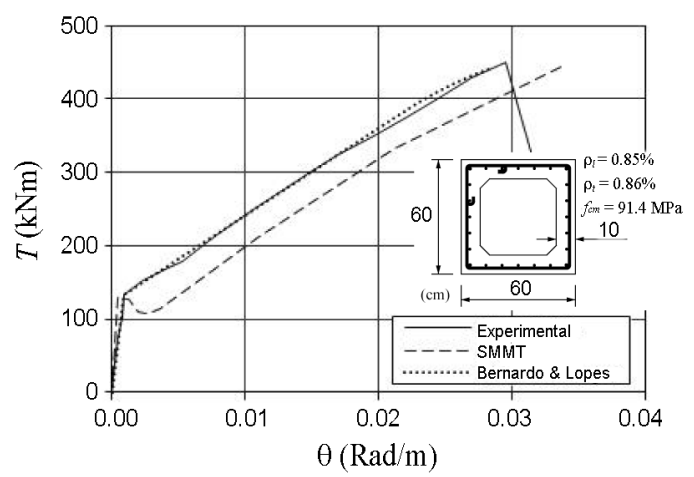

Fig. 18. $T-\theta$ curves for Beam $\mathrm{C} 4$

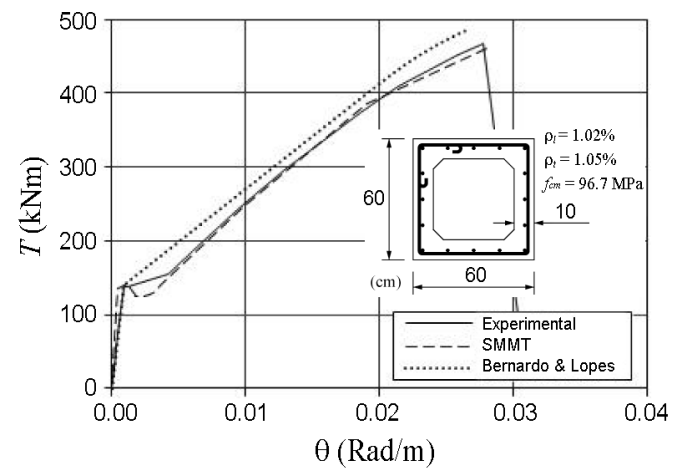

Fig. 19. $T-\theta$ curves for Beam C5

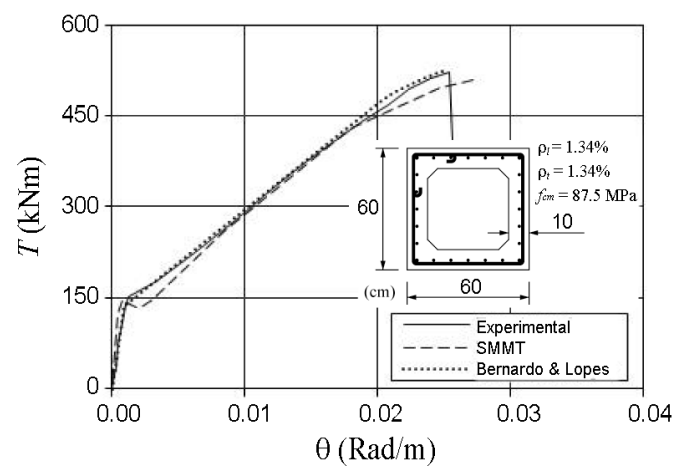

Fig. 20. $T-\theta$ curves for Beam C6

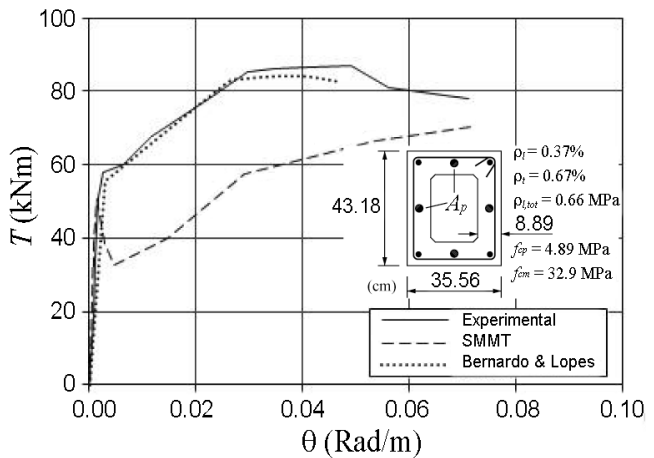

Fig. 21. $T-\theta$ curves for Beam P2

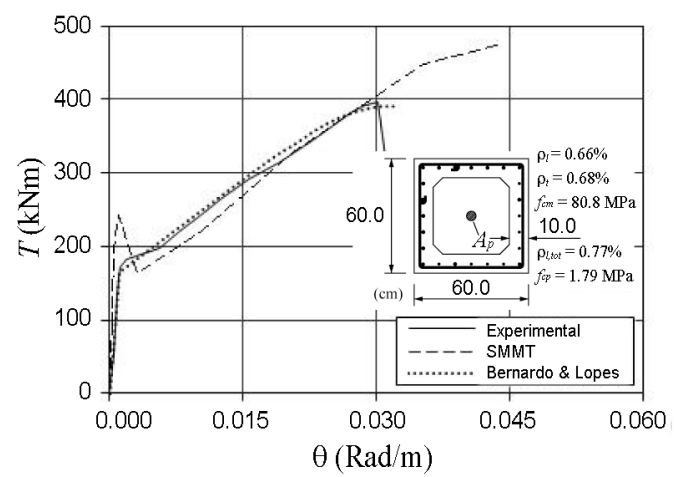

Fig. 22. $T-\theta$ curves for Beam D1

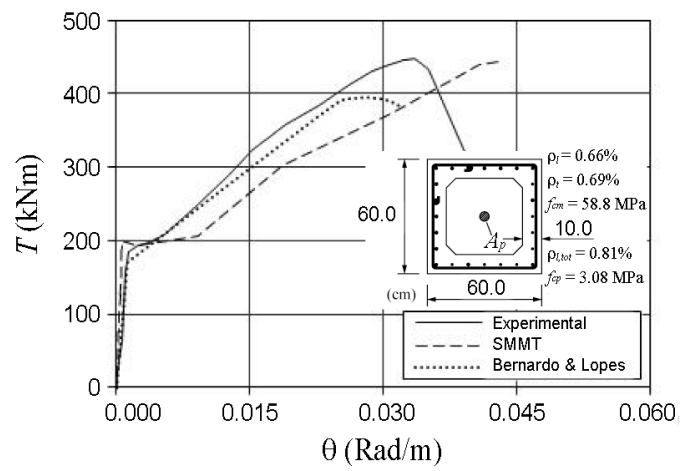

Fig. 23. $T-\theta$ curves for Beam D2

PC beams were analyzed. For Beam P2, the post-cracking $T-\theta$ curves do not fit the experimental one. Figures 21 to 23 show again that the theoretical curves from the global model of Bernardo and Lopes $(2008,2011 b)$ are closer to the experimental ones.

\section{Conclusions}

In this study, the SMMT proposed and validated by Jeng, Hsu (2009) and Jeng et al. (2010) for solid beams was checked for RC and PC hollow beams.

For the pre-cracking $T-\theta$ curve, it was observed that the correction (increasing 45\%) proposed by Jeng, Hsu (2009) for pre-cracking stiffness $\left(E_{c}\right)$ and the strain at peak stress $\left(\varepsilon_{c r}\right)$, for RC solid beams, is no longer valid for hollow beams because the theoretical cracking torques are overestimated. Based on a parametric study, a new correction factor (increasing 24\%) for RC hollow sections is proposed in this study to correct the theoretical cracking torques. With this proposal, the theoretical pre-cracking $T-\theta$ curves agree well with the experimental ones. 
SMMT model shows some difficulty to predict well the position of the $T-\theta$ curve for the cracking state, mainly for beams with lower reinforcement ratio. This is due to the theoretical sudden "fall" of the $T-\theta$ curve after cracking. This is not observed in the experimental $T-\theta$ curves neither in the theoretical $T-\theta$ curves from the model of Bernardo, Lopes 2008. In the author's opinion this behaviour is related with the $\sigma-\varepsilon$ relationship shape for concrete in tension (Table 3). The sudden "fall" of the $\sigma-\varepsilon$ curve after the concrete cracking is reflected into the $T-\theta$ curve. Note that the model of Bernardo and Lopes (2008) do not incorporate the $\sigma-\varepsilon$ relationship for concrete in tension. Usually, average $\sigma-\varepsilon$ relationships for concrete in tension are based on tests of RC prisms under tension. For this reason, some stress transfer phenomena (that take place when the concrete cracks) are not taken into account, such as the stress transfer to the reinforcement by shear (in beams under torsion the cracks are inclined with respect to the bars). New and realistic relationships for concrete in tension should be studied for beams under torsion.

The results of this study show that the previsions from SMMT for the ultimate state are good. This results show that the correction of the Hsu/Zhu ratio for torsion, as proposed by Jeng, Hsu (2009) for torsion and for solid beams, remains valid for hollow beams.

For PC beams, no solid conclusions could be established. This is mainly due to the insufficient number of experimental beams.

When compared with SMMT, the global model of Bernardo and Lopes (2008) is better. However, this latter is less rational because is based in more than one theory.

The study on the torsional behaviour of RC and PC solid/hollow beams should continue in order to improve the theoretical models.

\section{References}

Belarbi, A.; Hsu, T. T. C. 1994. Constitutive laws of concrete in tension and reinforcing bars stiffened by concrete. $A C I$ Structural Journal 91(4): 465-74.

Bernardo, L. F. A. 2003. Torsion in reinforced high-strength concrete hollow beams. PhD Thesis, University of Coimbra, Portugal. (in Portuguese).

Bernardo, L. F. A.; Lopes, S. M. R. 2008. Behaviour of concrete beams under torsion - NSC solid and hollow beams, Journal Materials and Structures. RILEM. Springer. 41(6): 1143-67.

Bernardo, L. F. A.; Lopes, S. M. R. 2009. Torsion in HSC hollow beams: strength and ductility analysis, ACI Structural Journal 106(1): 39-48.
Bernardo, L. F. A.; Lopes, S. M. R. 2011a. High-strength concrete hollow beams strengthened with external transversal steel reinforcement under torsion, Journal of Civil Engineering and Management 17(3): 330-339. http://dx.doi.org/10.3846/13923730.2011.589204

Bernardo, L. F. A.; Lopes, S. M. R. 2011b. Theoretical behaviour of HSC sections under torsion, Engineering Structures 33(12): 3702-3714. http://dx.doi.org/10.1016/j.engstruct.2011.08.007

CEB. 1969. Torsion. Bulletin d'Information No. 71.

Hsu, T. T. C. 1968 . Torsion of structural concrete - behaviour of reinforced concrete rectangular members, Torsion of Structural Concrete. ACI SP-18/-10 18: 261-306.

Hsu, T. T. C.; Mo, Y. L. 1985a. Softening of concrete in torsional members - theory and tests, ACI Journal Proceedings 82(3): 290-303.

Hsu, T. T. C.; Mo, Y. L. 1985b. Softening of concrete in torsional members - prestressed concrete, ACI Journal Proceedings 82(5): 603-615.

Hsu, T. T. C.; Zhu, R. R. H. 2002. Softened membrane model for reinforced concrete elements in shear, ACI Structural Journal 99(4): 460-469.

Jeng, C. H.; Chiu, H. J.; Chen, C. S. 2010. Modelling the initial stresses in prestressed concrete members under torsion, ASCE Conference Proceedings 369, 162: 1773-1781.

Jeng, C. H.; Hsu, T. T. C. 2009. A softened membrane model for torsion in reinforced concrete members, Engineering Structures 31(9): 1944-1954. http://dx.doi.org/10.1016/j.engstruct.2009.02.038

Lampert, P.; Thurlimann, B. 1969. Torsion tests of reinforced concrete beams. Bericht Nr. 6506-2. Institut fur Baustatik, ETH. Zurich. (in German).

Leonhardt, F.; Schelling, G. 1974. Torsionsversuche an Stahl Betonbalken. Bulletin No. 239. Deutscher Ausschuss fur Stahlbeton. Berlin. (in German).

Mitchell, D.; Collins, M. P. 1974. The behaviour of structural concrete beams in pure torsion, Civil Engineering Publication No.74-06, University of Toronto, Canada.

NP EN 1992-1-1. 2010. Eurocode 2: design of concrete structures - part 1: general rules and rules for buildings.

Ramberg, W.; Osgood, W. R. 1943. Description of stress-strain curves by three parameters, Technical Note No. 902. Washington DC: National Advisory Committee For Aeronautics.

Rausch, E. 1929. Design of reinforced concrete in torsion. PhD Thesis, Berlin. (in German).

Wang J. 2006. Constitutive relationships of prestressed concrete membrane elements. $\mathrm{PhD}$ Thesis, University of Houston, TX, USA.

Zhu, R. R. H.; Hsu, T. T. C. 2002. Poisson effect in reinforced concrete membrane elements, ACI Structural Journal 99(5): 631-640.

Luís F. A. BERNARDO. He is an Assistant Professor at the Department of Civil Engineering and Architecture of the University of Beira Interior, Portugal. He is a member of the research Centre C-made: Centre of Materials and Building Technologies, Portugal. His research interests include the mechanical behaviour of structural concrete and the development of new structural materials and new building systems.

Jorge M. A. ANDRADE. He is an Assistant Professor at the Department of Civil Engineering and Architecture of the University of Beira Interior, Portugal. He is a member of the research Centre C-made: Centre of Materials and Building Technologies, Portugal. His research interests include the behaviour of steel, aluminum and reinforced concrete structural elements, mainly numerical simulations of problems.

Luiz A. PEREIRA-DE-OLIVEIRA. He is an Associate Professor of Faculty of Engineering at the University of Beira Interior, Portugal. He is a member of CIB-W115 Commission, Construction Materials Stewardship. His research interests include the technology of concrete and masonry structures, particularly the composites rheological behaviour and hi-value wastes materials and components. 